http://doi.org/10.11646/zootaxa.4173.2.4

http://zoobank.org/urn:lsid:zoobank.org:pub:92235C7E-F276-4238-AD81-7ED7E49E65C1

\title{
New species of tree cricket Oecanthus Serville, 1831 (Orthoptera: Gryllidae: Oecanthinae) from Reserva Natural Vale, Espírito Santo, Brazil, with chromosome complement
}

\author{
ELISA MACHADO MILACH ${ }^{1}$, MARIA KÁTIA MATIOTTI DA COSTA ${ }^{2}$, LUCIANO DE PINHO MARTINS 3 , \\ LORENA ANDRADE NUNES ${ }^{4}$, DANIELA SANTOS MARTINS SILVA', \\ FLÁVIO ROBERTO MELLO GARCIA ${ }^{1}$, ELLIOTT CENTENO DE OLIVEIRA ${ }^{1} \&$ EDISON ZEFA ${ }^{1,6}$ \\ ${ }^{l}$ Programa de Pós-Graduação em Entomologia, Depto. de Ecologia, Zoologia e Genética, IB, Universidade Federal de Pelotas, \\ Capão do Leão s/n., 96010-900, Brazil \\ ${ }^{2}$ Pontificia Universidade Católica do Rio Grande do Sul - Faculdade de Biociências - Depto. de Biodiversidade e Ecologia - Lab. de \\ Entomologia \\ ${ }^{3}$ Instituto Nacional de Pesquisas da Amazônia (INPA), Coordenação de Biodiversidade, av. André Araújo, 2936, 69060-001, Manaus, \\ Amazonas, Brazil \\ ${ }^{4}$ Universidade Estadual do Sudoeste da Bahia. Rua José Moreira Sobrinho sn, Jequiezinho, Jequié -BA \\ ${ }^{5}$ Programa de Pós-Graduação em Ecologia, Depto. de Biologia Geral, Universidade Federal de Viçosa, Campus Universitário, Av.PH \\ Rolfs $s / n$, Viçosa, Brazil \\ ${ }^{6}$ Corresponding author. E-mail: edzefa@gmail.com
}

\begin{abstract}
A new species of the genus Oecanthus Serville, 1831 from Reserva Natural Vale, state of Espírito Santo, Brazil is described. The new species differs from other of this genus in characteristics of the pseudepiphallus main lobe, endophallic sclerites, posterior median lobe of the metanotal gland and black spots on the femora and tibiae. The chromosome number is $2 n=16+X Y \hat{o}=18$ and $2 n=16+X X O=18$, and this complement present one pair of autosomes less than the other five cytological studied species.
\end{abstract}

Key words: Insect, Ensifera, taxonomy, cytogenetic, metanotal gland, genitalia

\section{Introduction}

The subfamily Oecanthinae includes 169 valid species, arranged in two tribes: Xabeini Vickery \& Kevan, 1983 with five genera and 95 species and Oecanthini Blanchard, 1845 with three genera and 74 species. Between Oecanthini's genera, Oecanthus Serville, 1831 is the most representative with 69 valid species (Eades et al. 2016).

Six species of Oecanthus were described from Brazil, O. minutus Saussure, 1878 from state of Pernambuco, $O$. pictipes Rehn, 1917 state of Rio Grande do Norte, O. tenuis Walker, 1869 state of Pará, and O.pallidus Zefa, 2012, O. lineolatus Saussure, 1897 and O. pictus Milach \& Zefa, 2015, last three from state of Rio Grande do Sul, and collected on a tobacco plantation (Zefa et al. 2012; Milach et al. 2015). According to our field experience there may be more than one hundred of undescribed species in different Brazilian biomes.

Almost all Oecanthus species are pale green or brown, with translucent tegmina. Species diagnosis usually is done by combining scape and pedicel marks, with calling song parameters, tegmina, metanotal gland, phallic sclerites, and chromosomes (Walker 1963; Toms \& Otte 1988; Metrani \& Balakrishnan 2005; Zefa et al. 2012; Milach et al. 2015).

To date only five of the 69 valid species had their chromosomes studied, focusing brief description of the chromosome number and the sex system. Oecanthus indicus Saussure, 1878, O. nigricornis Walker, 1869 and $O$. quadripunctatus Beutenmüller, 1894 present $2 \mathrm{n}=19$, X0 (Johnson 1931; Ohmachi 1935; Kitada 1949), and $O$. longicauda Matsumura, 1904 and O. pellucens (Scopoli, 1763) show 2n =20, XY (Ohmachi 1927, 1935; Makino 
1932, Hewitt 1979). All of them share the same asymmetric karyotype, with a chromosome group composed by large autosomes plus sexual X, and the other by small autosomes plus sexual Y (Johnson 1931; Makino 1932; Ohmachi 1927, 1935, Kitada 1949).

We found many individuals of tree crickets bordering the highway BR101 with conservation area "Reserva Natural Vale", municipality of Linhares, Espírito Santo state, Brazil. Specimens shown pale green body and a conspicuous black line on scape and pedicel, similar those found in $O$. pallidus and O. lineolatus from southern Brazil (Zefa et al. 2012), but smaller in body size.

In the present paper, we describe a new species of tree crickets from Reserva Natural Vale as a new species of Oecanthus, highlighting metanotal glands, and phallic sclerites. We also provide photography of males and females in vivo, and present the diploid chromosome number and sex system.

\section{Material and methods}

Specimens were collected in shrubs and grasses with a sweep net, bordering the highway BR101 alongside to the conservation area "Reserva Natural Vale", municipality of Linhares, state of Espírito Santo, Brazil (1905'817"S, 04003'116”'W), 28.vii.2012.

The right tegmen of the fifteen males was extracted, mounted on glass slides with a coverslip to obtain the number of teeth in the stridulatory file, as well as file length, mirror and harp area, dorsal field length and width, and the number of accessory veins.

The following body and metanotal gland characteristics were measured using a Zeiss Discovery V20 stereomicroscope with Axio Vision system: body length, pronotum length and width, head width, interocular distance, tibia and femur III length, metanotal gland length and width, scutellum cavity area, scutum and scutellum area, lenght and width.

Male genitalia were dissected and treated with an aqueous solution of $10 \% \mathrm{KOH}$ to remove muscle tissue, and sclerites were placed in Petri dishes with glycerin, and then analyzed through a stereomicroscope. Photographs and measurements were obtained under a Discovery V20 Zeiss stereomicroscope, equipped with Axio Vision system. Genitalia terminology was proposed by Desutter (1987) and modified by Desutter-Grandcolas (2003).

Male meiotic cells were obtained from testes dipped in a $\mathrm{KCl}$ hypotonic solution $(0.075 \mathrm{M})$ for five minutes before the fixation in Carnoy I. Slides were prepared by squashing tissues in $45 \%$ acetic acid, and cells were stained with $0.5 \%$ lacto-acetic orcein.

Depository. Holotype and 25 paratypes (14 adult males and 11 adult females) were deposited in the "Museu de Zoologia da Universidade de São Paulo (MZUSP)".

\section{Results}

\section{Oecanthus valensis Milach \& Zefa, n. sp.}

(Figs 1-2)

http://lsid.speciesfile.org/urn:lsid:Orthoptera.speciesfile.org:TaxonName:492154

Type material. Holotype ${ }^{\lambda}$ : Brazil, state of Espírito Santo, municipality of Linhares, Reserva Natural Vale, $19^{\circ} 05^{\prime} 817^{\prime \prime}$, $040^{\circ} 03$ '116”'W, 28.vii.2012, Nunes, L. \& Silva, D. leg. MZUSP. Holotype condition: hind legs were detached, and maintained in holotype's tube. Paratypes: same data of Holotype $(18 \hat{\jmath}, 11 \propto$, MZUSP).

Etymology. Specific epithet refers to the type locality: Reserva Natural Vale, a conservation area located in the municipality of Linhares, state of Espírito Santo, Brazil.

Diagnosis. Combination of the following characteristics: pseudepiphallic main lobe V-shaped indented (Figs 25-27, MLPs); ectophallic sclerite posteriorly U-shaped (Figs 29-30); posterior median lobe of the metanotal gland dorso-porsteriorly bended (Fig. 7, pml); apex of femora I, II and III with a pair of black lines in ventral face (Figs 13, 17, empty arrow); base of the tibiae I, II and II marked with a black dot in dorsal face (Figs 13, 15, black arrow). 


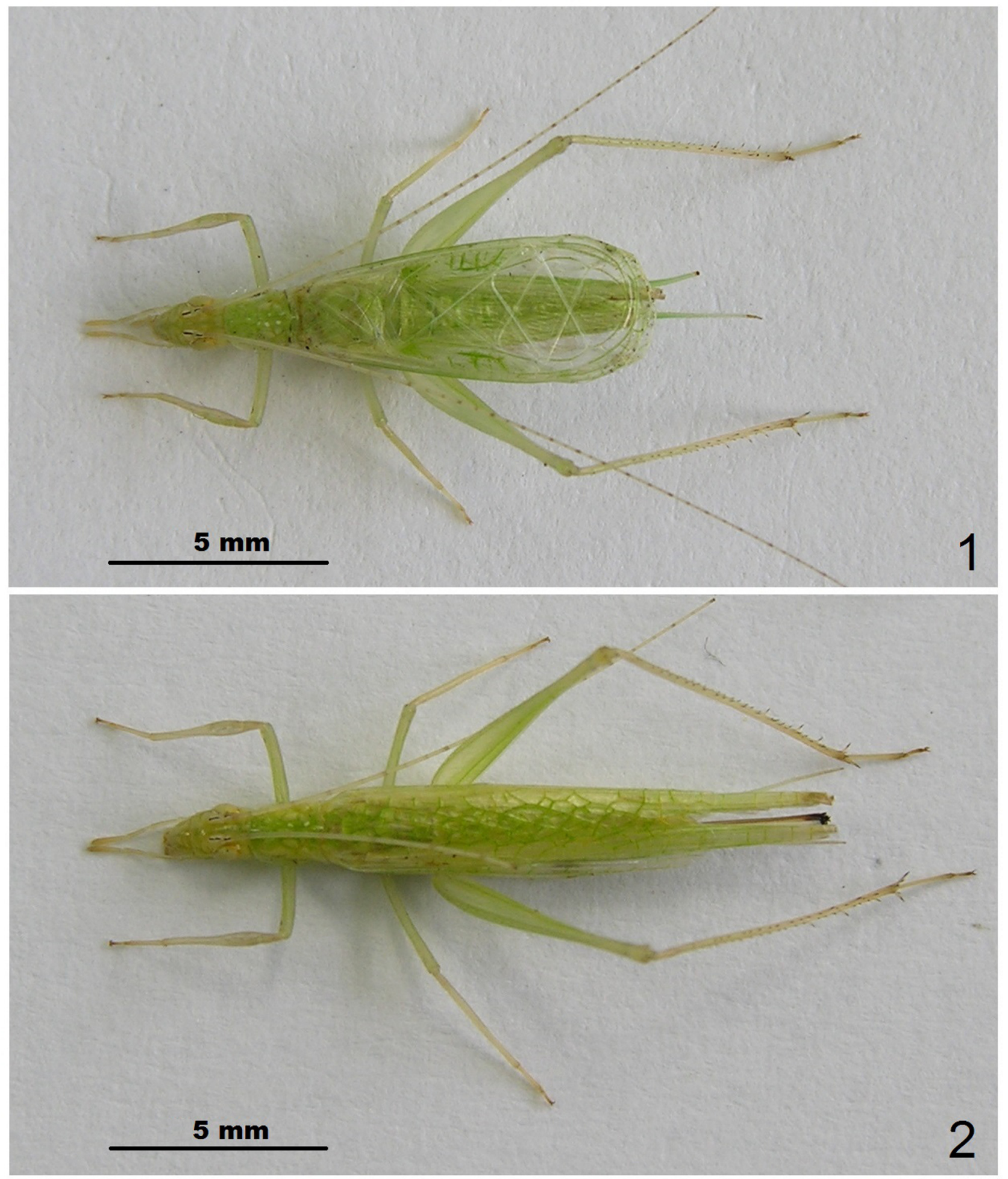

FIGURES 1-2. Habitus of Oecanthus valensis n. sp. in vivo. 1-male paratype, dorsal view; 2-female paratype, dorsal view.

Description, male Holotype (Figs 3-11). Body slender, light green with legs slightly lighter on the tips. Head: bristles between antennal scapes, vertex with bristles along ecdysial suture; yellowish-green eyes in vivo, becoming depigmented or black when fixed in alcohol, depigmented ommatidia where lies the scape; ocelli absent; scape and pedicel on ventral face marked with a longitudinal black line outlined by white (Fig. 12), antennal flagellum alternating darker and lighter rings from the middle region to the apex (Fig. 1); maxillary palpi five-jointed moderately elongate, first and second joints subequal, both together with the half length of the third joint, third to fifth joints subequal, last claviform (Fig. 12); labial palpi three-jointed, gradual increase in size toward the apex, 

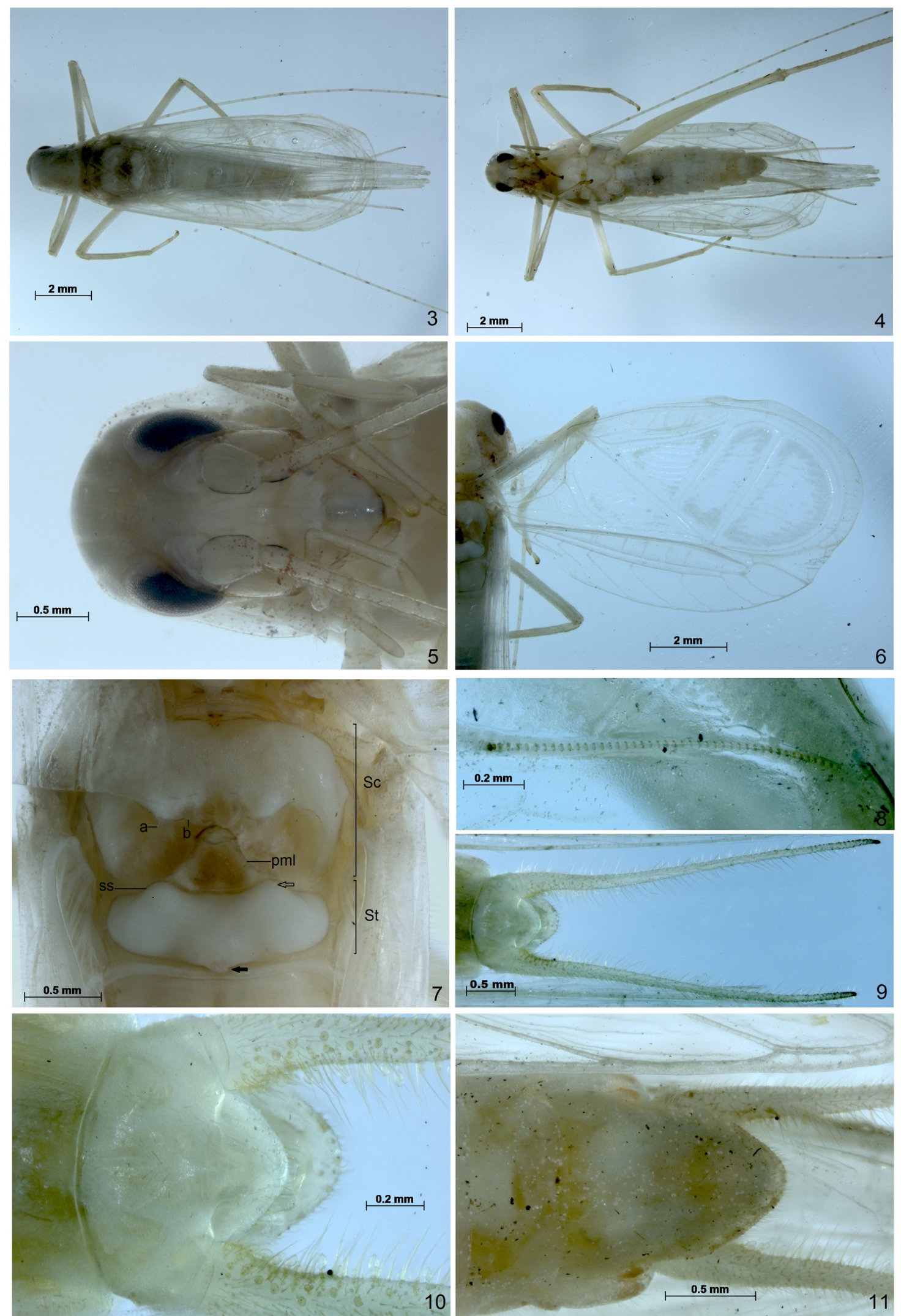

FIGURES 3-11. Main morphological characteristics of Oecanthus valensis n. sp. holotype. 3-4-habitus after alcohol fixation, in dorsal and ventral views, respectively; 5-head, frontal view; 6-right tegmen, dorsal view; 7 -metanotal gland, dorsal view; 8-stridulatory file; 9-cerci; 10-supranal plate; 11-subgenital plate. Conventions: Sc - scutum; Stscutellum; ss—scutoscutellar suture; pml—posterior median lobe; a - tuft of bristles projected posteriorly; b — bristles projected inward; empty arrow—scutellum lobe; black arrow—scutellum posterior median-projection. 

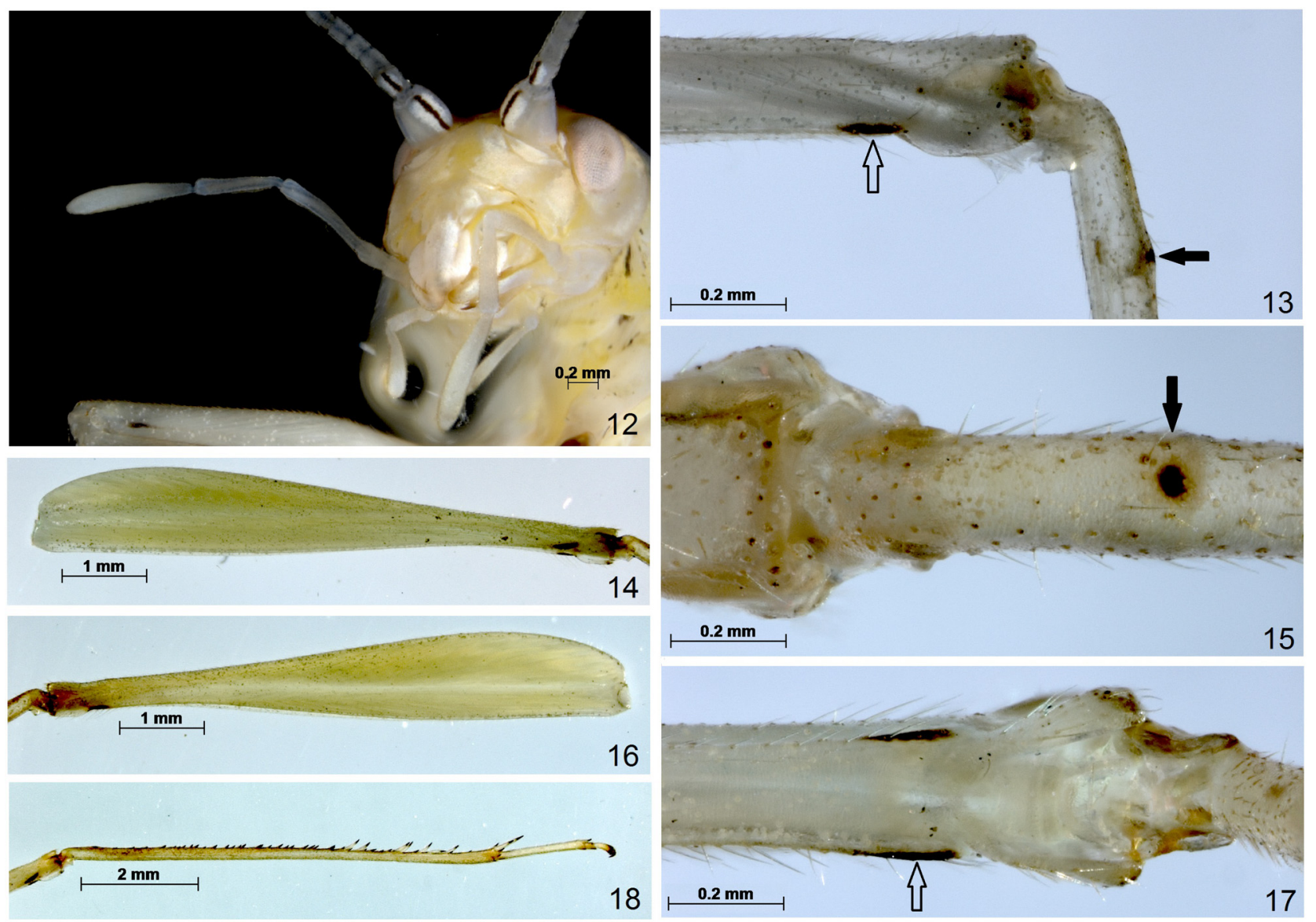

FIGURES 12-18. Main morphological characteristics of Oecanthus valensis $\mathbf{n}$. sp. paratypes. 12-Head, diagonal view; 13femur/tibia III joint, inner face; 14 - femur III, outer face; 15-tibia III, proximal black dot, dorsal view; 16-femur III, inner face; 17-femur III apex, black lines, ventral view; 18 - tibia III, lateral view. Conventions: black arrow-tibae black dot; empty arrow-femur black lines.

third claviform (Fig. 12). Thorax: pronotum translucent, slightly pubescent, longer than wide, bristles on the posterior border; tegmina translucent, longer than the abdomen; hind wings translucent longer than abdomen, surpassing tegmina length (Figs 3-4). Legs: apex of the femora I, II and III marked with a pair of black lines in ventral face (Figs 13, 17, empty arrow); tibiae I with auditory tympani elliptical, inner longer $(0.76 \mathrm{~mm})$ than outer $(0.57 \mathrm{~mm})$; base of the tibiae I, II and III marked with a black dot in dorsal face (Figs 13, 15, black arrow); tibiae III serrulated, armed with three pairs of subapical spurs tipped with black in both faces, and three apical spurs at outer and four at inner face; tarsus three-jointed, basitarsus lighter, longer than two others together, armed with two apical spurs (Fig. 18). Abdomen: cerci slender, shorter than the abdomen, tipped with black (Fig. 9); supranal (Fig. 10) and subgenital (Fig. 11) plates rounded posteriorly.

Metanotal Gland (Fig. 7). Scutum with a pit wide, and a pair of inflated protuberance (Fig. 7, Sc), each bearing a dense tuft of bristles projected posteriorly (Fig. 7, a), and a tuft of bristles projected inward (Fig. 7, b); posterior median lobe triangular with apex curved dorsoposteriorly (Fig. 7, St); scuto-scutellar suture sinuous, without bristles (Fig. 7, ss); scutellum with a projected pair of lobes (Fig. 7, empty arrow), and a posterior medianprojection (Fig. 7, black arrow). Measurements: gland length $1.62 \mathrm{~mm}$; gland width $1.71 \mathrm{~mm}$; cavity area $0.46 \mathrm{~mm}^{2}$; scutum area $1.59 \mathrm{~mm}^{2}$; scutum length $1,09 \mathrm{~mm}$; scutum width $1.73 \mathrm{~mm}$; scutellum area $0.6 \mathrm{~mm}^{2}$; scutellum lenght $0.49 \mathrm{~mm}$; scutellum width $1.44 \mathrm{~mm}$.

Rigth tegmen (Fig. 6). dorsal field length $9.8 \mathrm{~mm}$, dorsal field width $3.9 \mathrm{~mm}$; lateral field well developed, with eight accessory veins; median fan reduced; stridulatory file with 44 teeth, stridulatory file length $1.17 \mathrm{~mm}$ and 37.6 teeth per millimeter; harp area $6.53 \mathrm{~mm}^{2}$, harp with three cross veins slightly sinuous; mirror area $15.9 \mathrm{~mm}^{2}$, mirror with two straight cross veins; apical area reduced.

Measurements (mm). body length 10.3; pronotum length 2.04, pronotum width 1.78; head width 1.4; interocular distance 0.58 ; femur III length 6.78; tibia III length 7.42; cerci length 3.76; abdomen length 5.6. 

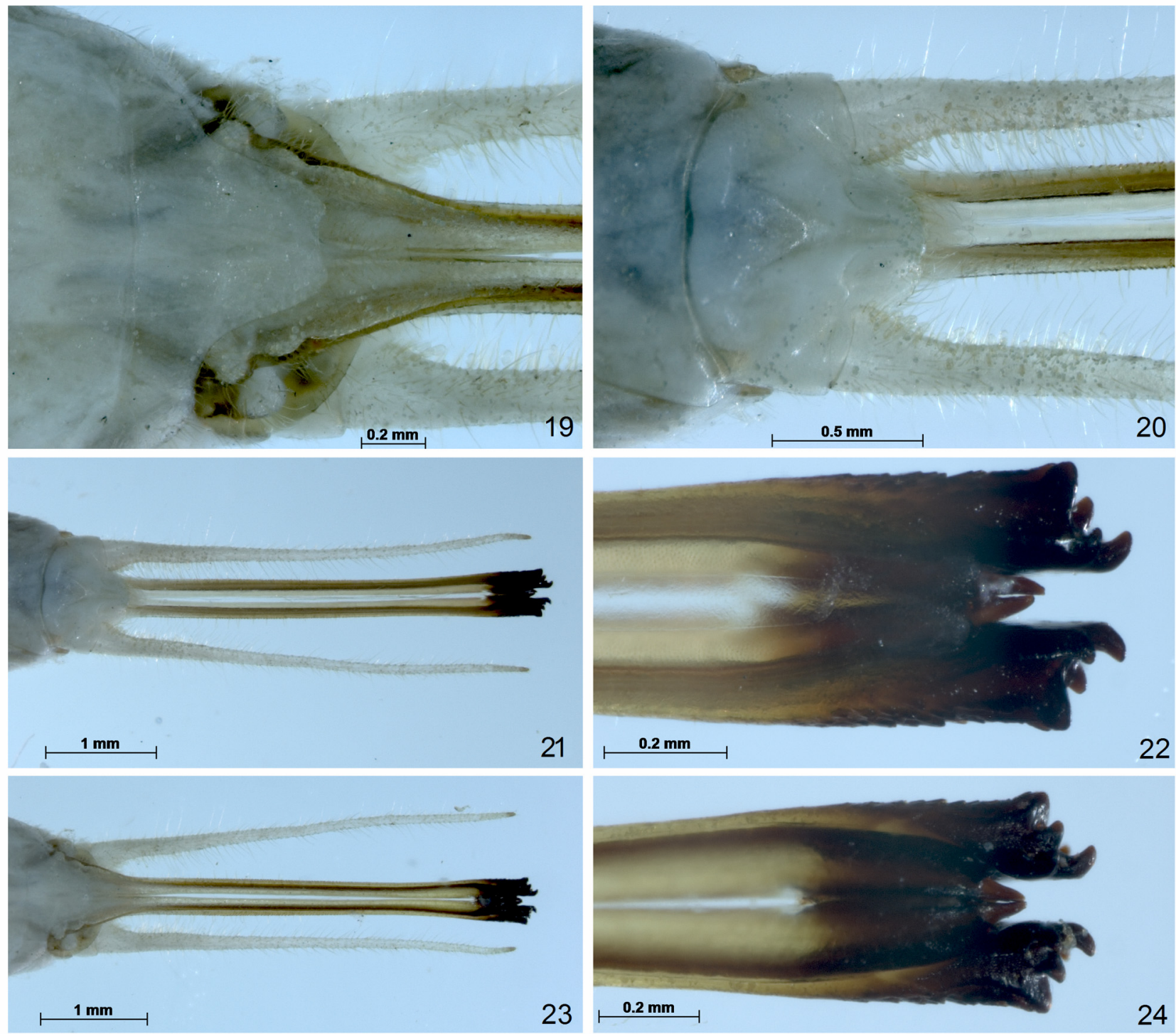

FIGURES 19-24. Main morphological characteristics of Oecanthus valensis n. sp., paratype female. 19—subgenital plate; 20 - supranal plate; 21 - cerci and ovipositor, dorsal view; 22- ovipositor tip, dorsal view; 23 - cerci and ovipositor, ventral view; 24- ovipositor tip, ventral view.

\section{Observations of Paratypes.}

Metanotal Gland Measurements ( $\mathrm{n}=17)$ : gland length $1.5 \mathrm{~mm} \pm 0.06$ (1.4-1.6); gland width $1.5 \mathrm{~mm} \pm 0.08$ (1.4-1.7); scutum area $1.4 \mathrm{~mm}^{2} \pm 0.11$ (1.2-1.5); scutum length $1.1 \mathrm{~mm} \pm 0.05$ (1-1.1); scutum width $1.5 \mathrm{~mm} \pm 0.08$ (1.4-1.7); scutellum area $0.52 \mathrm{~mm}^{2} \pm 0.05(0.43-0.64)$; scuttelum length $0.46 \mathrm{~mm} \pm 0.04(0.4-0.53)$; scutellum width $1.3 \mathrm{~mm} \pm 0.05(1.2-1.4)$.

Rigth tegmen $(\mathrm{n}=14)$. Dorsal field length $9.3 \mathrm{~mm} \pm 0.38$ (8.3-9.7); dorsal field width $3.8 \mathrm{~mm} \pm 0.30$ (3.1-4.1); mirror area $12.1 \mathrm{~mm}^{2} \pm 1.22$ (9.7-14.2); harp area $6.2 \mathrm{~mm}^{2} \pm 0.49$ (5.3-7); number of accessory veins $12.2 \pm 0.94$ (1013); file length $1.13 \mathrm{~mm} \pm 0.7$ (1-1.3); file teeth number $41.6 \pm 2.27$ (38-46).

Male genitalia (Figs 25-30). Similar as $O$. pictus (Milach et al. 2015), differing in pseudepiphallic main lobe with triangular lobes and rounded apex, and ectophallic sclerite posteriorly U-bifurcate with inner branches forming an ectophallic fold.

Female (Figs 2, 19-24). Body color similar to males, slightly longer than males; subgenital and supranal plates as Figures 19 and 20, respectively; ovipositor apex denticulate (Figs 21-24).

Male and Female Measurements in Table 1. 
TABLE 1. Measurements (mm) of the male and female paratypes of Oecanthus valensis $\mathbf{n} . \mathbf{s p}$.

\begin{tabular}{lll}
\hline Structure & Male & Female \\
\hline body length & $10.9 \pm 0.7(9.9-12.6, \mathrm{n}=18)$ & $11.2 \pm 0,83(10.1-12.5, \mathrm{n}=6)$ \\
pronotum length & $1.9 \pm 0.20(1.5-2.6, \mathrm{n}=22)$ & $1,8 \pm 0.09(1.6-1.9, \mathrm{n}=8)$ \\
pronotum width & $1.7 \pm 0.13(1.5-2, \mathrm{n}=22)$ & $1.7 \pm 0.10(1.6-1.9, \mathrm{n}=8)$ \\
head width & $1,5 \pm 0.06(1.3-1,6, \mathrm{n}=22)$ & $1.5 \pm 0.04(1.4-1.5, \mathrm{n}=8)$ \\
interocular distance & $0,52 \pm 0.03(0.48-0,6, \mathrm{n}=22)$ & $0.5 \pm 0.02(0.5-0.6, \mathrm{n}=8)$ \\
femur III length & $6,7 \pm 0.31(6-2, \mathrm{n}=21)$ & $6.6 \pm 0.24(6.3-7, \mathrm{n}=8)$ \\
tibia III length & $7,5 \pm 0.37(6.7-8, \mathrm{n}=20)$ & $7,4 \pm 0.31(6.8-7.8, \mathrm{n}=8)$. \\
cerci & $3,7 \pm 0.2(3.4-3.98, \mathrm{n}=7)$ & $4.2 \pm 0.39(3.71-5.05, \mathrm{n}=8)$ \\
ovipositor length & - & $4.3 \pm 0.23(3.85-4.6, \mathrm{n}=11)$ \\
\hline
\end{tabular}
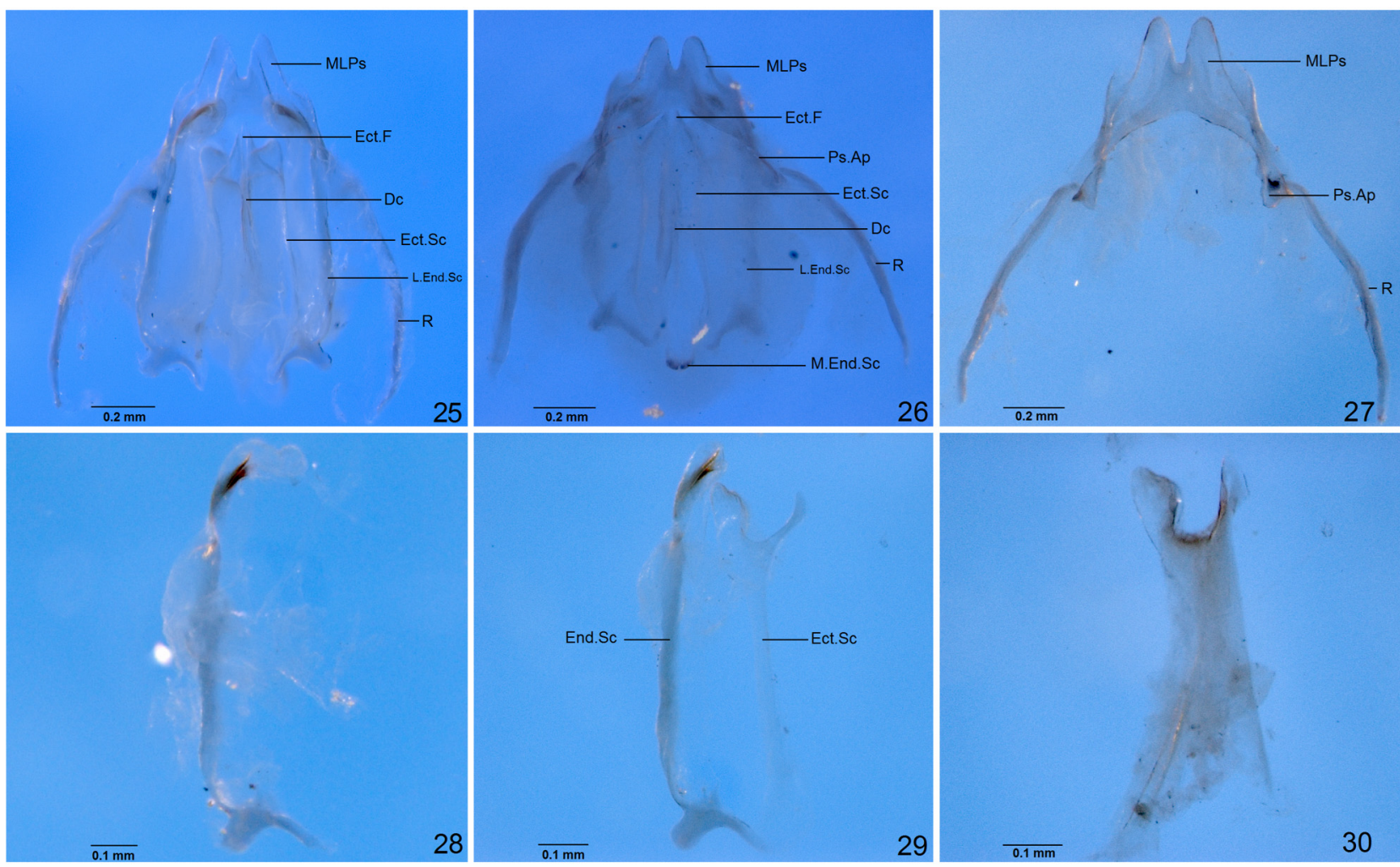

FIGURES 25-30. Male genitalia of Oecanthus valensis n. sp., paratype. 25-phallic sclerites, ventral view; 26-phallic sclerites, dorsal view; 27-pseudepiphallus, ventral view; 28-endophallic sclerite; 29 - ectophallic and endophallic sclerites; 30 - ectophallic sclerite. Conventions: MLPs - main lobe of pseudepiphallus; M.End.Sc — Median endophallic sclerite; L.End.Sc - lateral endophallic sclerite; End.Sc — endophallic sclerite; Ect.Sc_ectophallic sclerite; Ect.F-ectophallic fold; Ps.Ap.-Pseudepiphallic apodeme; Dc—dorsal cavity; R—rami.

Chromosomes (Figs 31-35). Diploid chromosome number of $2 \mathrm{n}=16+\mathrm{XY} \hat{\delta}=18$, and $2 \mathrm{n}=16+\mathrm{XX}$ q $=18$; two pairs of large metacentric/submetacentric autosome chromosomes, and six pairs of small dot-like autosomes, probably acrocentric, as well as a XY sex system composed by a large X chromosome and a small Y chromosome; one dot-like B chromosome may be present.

\section{Discussion}

The species here described has single pigmented spots on the legs I, II and III, being a black dot in the dorsal base of the tibiae, and a pair of shaped black marks in the ventral apex of the femur, the latter also observed in $O$. niveus 
(Eades et al. 2016). Few species have pigmented spots on the legs, among them is O. celerinictus Walker, 1963 with two transverse black marks near proximal end of the tibiae (Walker 1963), and O. bakeri Collins \& van den Berghe, 2014 bearing black half-circle on the femoral-tibial joints, and three black rows down the length of the femur (Collins et al. 2014). Considering these spots did not disappear after individual fixation in alcohol it becomes a good character for the determination of these species.

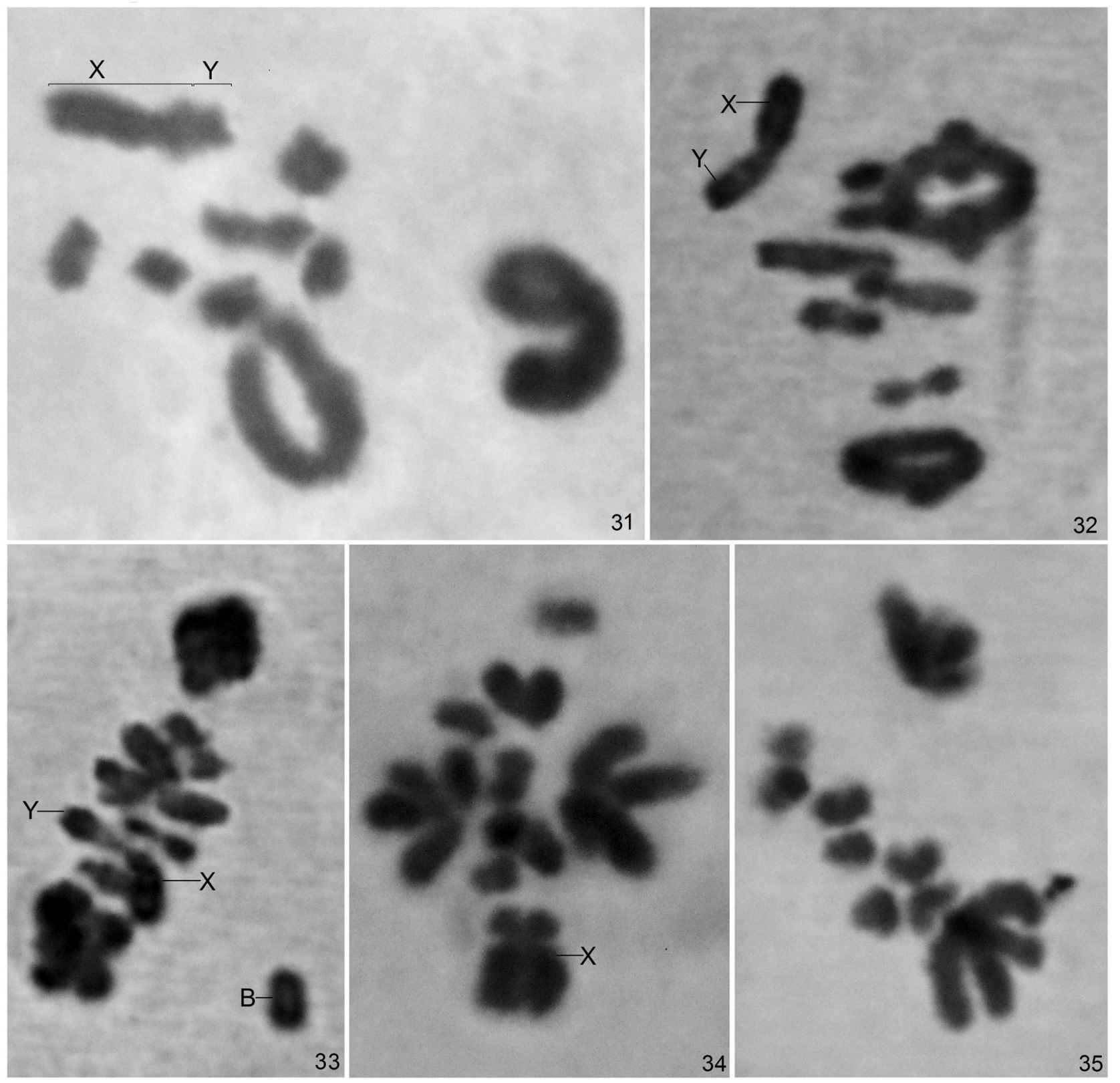

FIGURES 31-35. Male chromosomes of Oecanthus valensis n. sp. 31-Diplotene; 32-metaphasis I; 33-metaphasis I with B chromosome; 34 - metaphasis II with eight autosomes, plus the $\mathrm{X}$ and B chromosomes as one of the smaller ones; 35metaphasis II with eight autosomes and the $\mathrm{Y}$ as one of the smaller chromosomes.

The black straight line present in both the scape and the pedicel of $O$. valensis $\mathbf{n}$. sp. are similar to present in $O$. leptogrammus Walker, 1962 (Walker, 1962; Collins et al. 2014), O. exclamationis Davis, 1907 (Walker, 1962), O. californicus Saussure, 1874, O. bakeri (Collins et al. 2014), O. jamaicensis Walker, 1969, O. lineolatus (Zefa et al. 2012), O. pallidus (Walker, 1967; Zefa et al. 2012), O. minutus, O. pictipes (Rehn, 1917), O. symesi Collins \& van den Berghe, 2014 (Collins et al. 2014) and O. tenuis (Walker, 1967). This represents about 38\% of the twenty-nine described species that have some kind of marks on the scape and pedicel.

We found at literature thirty seven species of Oecanthus with metanotal gland described, and verified 
similarities in the bristles of the scutum, and morphology of posterior median lobe comparing O. valensis $\mathbf{n}$. sp. with Southern African species O. galpini Toms \& Otte, 1988, O. karschi Chopard, 1932 and O. filiger Walker, 1871 (Toms \& Otte, 1988).

The $O$. valensis n. sp. phallic complex is similar to species $O$. pictus, O. pallidus and $O$. lineolatus, all of them documented in Brazilian territory (Zefa et al., 2012; Milach et al. 2015.), differing on the pseudepiphallus morphology, since $O$. valensis n. sp. shows pseudepiphallic main lobe triangular with rounded apex, as well as ectophallic sclerite U-bifurcate. Later may be observed when sclerites are analyzed separately, as was done in this work, and also by Zefa et al. (2012) and Milach et al. (2015).

Considering the five species of Oecanthus cytologically studied, three are from Asia and two from North America. The Asiatic species $O$. longicauda, O. indicus and $O$. pellucens present X chromosome and three pairs of autosomes, all of them large and acrocentrics, and six pair of small dot like chromosomes (Ohmachi 1927, 1935; Makino 1932; Kitada 1949; Hewitt 1979). On the other hand, North American species O. quadripunctatus and $O$. nigricornis show $\mathrm{X}$ chromosome and two pairs of autosomes being large, meta or submetacentrics, as well as seven pairs of small acrocentrics (Johnson 1931; Ohmachi 1935; Kitada 1949). Oecanthus valensis n. sp. exhibits similar chromosomal complement to the North American species, however with a pair of autosomal chromosomes less. This reduction in chromosomal number may have been the result of a Robertsonian translocation involving two pairs of small autosomes. Although the small size of the dot-like autosomes did not allow us to recognize centromeric position to define chromosomal morphology, we suggest chromosome number reduction in $O$. valensis n. sp., since centric fusion is more abundant than fission in cytological studied species of Orthoptera (White \& Morley, 1955; White, 1978).

\section{Acknowledgements}

This paper has benefited from grants received from Conselho Nacional de Desenvolvimento Científico e Tecnológico (CNPq, Brazil) for the scholarship granted to Luciano de Pinho Martins (350059/2010-1 and 350059/ 2012-8), as well as financial support received from CNPq (Conselho Nacional de Desenvolvimento Científico e Tecnológico) and FAPEMIG (Fundação de Amparo Pesquisa do Estado de Minas Gerais) - Process number 563360/2010-0—EditalMCT/CNPq/MMA/MEC/ CAPES/FNDCT—Ação Transversal/FAPs N 47/ 2010 Sistema Nacional de Pesquisa em Biodiversidade—SISBIOTA Brasil.

\section{References}

Collins, N., van den Berghe, E. \& Carson, L. (2014) Two new species of Neoxabea, three new species of Oecanthus, and documentation of two other species in Nicaragua (Orthoptera: Gryllidae: Oecanthinae). Transactions of the American Entomological Society, 140 (1), 163-184. http://dx.doi.org/10.3157/061.140.0111

Desutter, L. (1987) Structure et évolution du complexe phallique des Gryllidea (Orthoptères) et classification des genres Néotropicaux de Grylloidea. Première Partie. Annales de la Société Entomologique de France, 23, 213-239.

Desutter-Grandcolas, L. (2003) Phylogeny and the evolution of acoustic communication in extant Ensifera (Insecta, Orthoptera.). Zoologica Scripta, 32, 525-561. http://dx.doi.org/10.1046/j.1463-6409.2003.00142.x

Eades, D.C., Otte, D., Cigliano, M.M. \& Braun, H. (2016) Orthoptera Species File Online. Version 5.0/5.0. [Cited 12 March 2016] Available from: http://Orthoptera.SpeciesFile.org (Accessed 3 Oct. 2016)

Hewitt, G.M. (1979) Orthoptera: Grasshoppers and crickets. In: John, B. (Ed.), Animal Cytogenetics 3. Insecta I. GebrüderBorntraeger, Berlin-Stuttgart, $170 \mathrm{pp}$.

Johnson, H.H. (1931) Centrioles and other cytoplasmic components of the male germ cells of the Gryllidae. Zeitschrift für wissenschaftliche Zoologie, 140, 115-166.

Kitada, S. (1949) Preliminary notes on the chromosomes of Oecanthus indicus. Kromosomo, 5-6, 227-228.

Makino, S. (1932) An unequal pair of idiochromosomes in the tree cricket Oecanthus longicauda. Journal of the Faculty of Science, Hokkaido University, VI (2), 1-36.

Metrani, S. \& Balakrishnan, R. (2005) The utility of song and morphological characters in delineating species boundaries among sympatric tree crickets of the genus Oecanthus (Orthoptera: Gryllidae: Oecanthinae): a numerical taxonomic approach. Journal of Orthoptera Research, Philadelphia, 14 (1), 1-16. http://dx.doi.org/10.1665/1082-6467(2005)14[1:TUOSAM]2.0.CO;2 
Milach, E.M, Martins, L.P., Costa, M.K.M., Gottschalk, M.S. Oliveira, G.L. Redü, D.R., Neutzling, A.S., Dornelles, J.E.F., Vasconcellos, L.A. \& Zefa, E. (2015) A new species of tree crickets Oecanthus (Orthoptera, Gryllidae, Oecanthinae) in tobacco plantation from Southern Brazil, with body color variation. Zootaxa, 4018 (2), 266-278. http://dx.doi.org/10.11646/zootaxa.4018.2.6

Ohmachi, F. (1927) Preliminary note on cytological studies on Gryllodea (Chromosome-numbers and sex-chromosomes of eighteen species.). Proceedings of the Imperial Academy, 3 (7), 451-56.

Ohmachi, F. (1935) A comparative study of chromosome complements in the Gryllodea in relation to taxonomy. Bulletin of the Miyazaki College of Agriculture and Forestry, 5, 1-48.

Rehn, J.A.G. (1917) On Orthoptera from the vicinity of Rio de Janeiro, Brazil. Transactions of the American Entomological Society (Philadelphia), 43 (1), pp. 131.

Toms, R.B. \& Otte, D. (1988) New genera, species and records of East and South African tree crickets (Orthoptera: Gryllidae: Oecanthinae). Annals of the Transvaal Museum, 34, 469-521.

Walker, T.J. (1962) The taxonomy and calling songs of United States tree crickets (Orthoptera: Gryllidae: Oecanthinae). I. The genus Neoxabea and the niveus and varicornis groups of the genus Oecanthus. Annals of the Entomological Society of America, 55, 303-322. http://dx.doi.org/10.1093/aesa/55.3.303

Walker, T.J. (1963) The taxonomy and calling songs of United States tree crickets (Orthoptera: Gryllidae: Oecanthinae). II. The nigricornis group of the genus Oecanthus. Annals of the Entomological Society of America, 56, 772-789. http://dx.doi.org/10.1093/aesa/56.6.772

Walker, T.J. (1967) Revision of Oecanthinae (Orthoptera: Gryllidae) of America south of the United States. Annals of the Entomological Society of America, 60, 784-796. http://dx.doi.org/10.1093/aesa/60.4.784

White, M.J.D. \& Morley, F.H.W. (1955) Effects of pericentric rearrangements on recombination in grasshopper chromosomes. Genetics, 40, 604-619.

White, M.J.D. (1978) Modes of Speciation. W.H. Freeman Ltd. 455p.

Zefa, E., Neutzling, A.S., Redü, D.R., Oliveira, G.L. \& Martins, L.P. (2012) A new species of Oecanthus and Oecanthus lineolatus Saussure, 1897 from Southern Brazil: species description, including phallic sclerites, metanotal glands and calling song (Orthoptera: Gryllidae: Oecanthinae). Zootaxa, 3360, 53-67. 